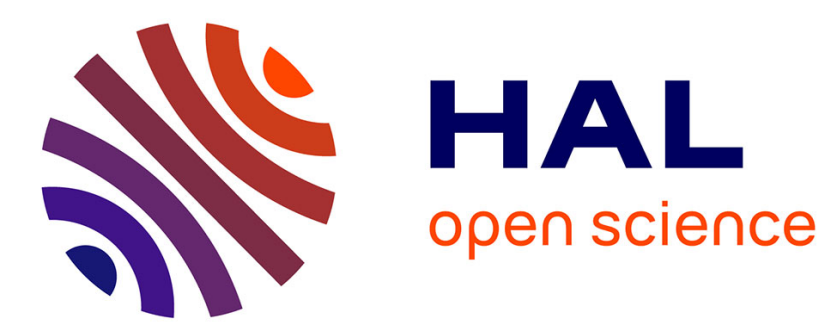

\title{
The modification of plant hormone level and signaling as a tool in plant biotechnology
}

Fabiana Csukasi, Catharina Merchante, Victoriano Valpuesta

\section{To cite this version:}

Fabiana Csukasi, Catharina Merchante, Victoriano Valpuesta. The modification of plant hormone level and signaling as a tool in plant biotechnology. Biotechnology Journal, 2009, 4 (8), pp.1293. 10.1002/biot.200800286 . hal-00498912

\section{HAL Id: hal-00498912 https://hal.science/hal-00498912}

Submitted on 9 Jul 2010

HAL is a multi-disciplinary open access archive for the deposit and dissemination of scientific research documents, whether they are published or not. The documents may come from teaching and research institutions in France or abroad, or from public or private research centers.
L'archive ouverte pluridisciplinaire HAL, est destinée au dépôt et à la diffusion de documents scientifiques de niveau recherche, publiés ou non, émanant des établissements d'enseignement et de recherche français ou étrangers, des laboratoires publics ou privés. 


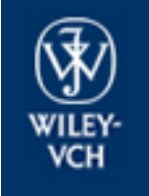

Biotechnology Journal

\section{The modification of plant hormone level and signaling as a tool in plant biotechnology}

\begin{tabular}{|r|l|}
\hline Journal: & Biotechnology Journal \\
\hline Manuscript ID: & BIOT-2008-0286.R2 \\
\hline Wiley - Manuscript type: & Review \\
\hline Date Submitted by the \\
Author: & 02-Jun-2009 \\
\hline Complete List of Authors: & $\begin{array}{l}\text { Csukasi, Fabiana; Universidad de Málaga, Biología Molecular y } \\
\text { Bioquímica } \\
\text { Merchante, Catharina; Universidad de Málaga, Biología Molecular y } \\
\text { Bioquímica } \\
\text { Valpuesta, Victoriano; Universidad de Málaga, Departamento de } \\
\text { Biología Molecular y Bioquímica }\end{array}$ \\
\hline Keywords: & plant hormones, agricultural traits, transgenic, mutants, signaling \\
\hline
\end{tabular}

\section{s ScholaroNE" \\ Manuscript Central}


Review ((8878 words))

Modification of plant hormone levels and signaling as a tool in plant biotechnology

\section{Fabiana Csukasi, Catharina Merchante and Victoriano Valpuesta}

Departamento de Biología Molecular y Bioquímica, Universidad de Málaga, 29071 Málaga, Spain

Keywords: plant hormones, agricultural traits, transgenic, mutants, signaling

Corresponding author:

Victoriano Valpuesta

Professor

Departamento de Biología Molecular y Bioquímica, Univesidad de Málaga, 29071 Málaga, Spain

Phone: 34952131932

Fax: 34952134267

e-mail: valpuesta@uma.es 


\section{Abstract}

Plant hormones are signal molecules, present in trace quantities that act as major regulators of plant growth and development. They are involved in a wide range of processes such as elongation, flowering, root formation and vascular differentiation. For many years, agriculturists have applied hormones to their crops to either increase the yield, or improve the quality of the commercial product. Nowadays, the knowledge of hormone biosynthesis, degradation and signaling pathways has allowed the utilization of biotechnological tools to improve even more the main agricultural crops. Natural or artificial mutants, with impaired functioning of the corresponding genes, have been adopted by their superior phenotype in specific agricultural traits. Also, transgenic plants have been generated to regulate internal hormone levels, or their signaling pathways, resulting in some crops that have revolutionized the agriculture. 


\section{Introduction}

Plant hormones are signal molecules, present in trace quantities that act as major regulators of plant growth and development. Changes in concentration and cell/tissue sensitivity have dramatic effects in the physiology of the plant. This is a consequence of the fact that they participate in many different developmental processes that range from general growth, to flowering, root formation and vascular differentiation [1]. External application of these hormones has been for many years the procedure used in many agricultural crops to either increase the yield, or to improve the quality of the commercial product [2]. Nowadays, biochemical studies and genetic dissections have supported new insights into the molecular mechanisms of hormone biosynthesis and signal transduction pathways $[3,4]$. This new information has allowed affording with new tools the improvement of main agricultural crops.

Known plant hormones are auxin, gibberellins, cytokinins, abscisic acid, ethylene, brassinosteroids, and more recently strigolactones [5, 6]. Not all of them have received the same attention as putative targets for plant biotechnology. Effectively, structural diversity of hormones is high, and so is the complexity of the metabolic pathways for their synthesis and catabolism, and not all of them are completely known [3]. The biggest aim of plant hormones Biotechnology has been to modulate their internal concentrations in a tissue/development specific manner. This is achieved after modification of either synthesis or degradation pathways, or both, since steady state level results from the net balance of these two processes. The second limitation has been determined by the same complexity of the signaling pathways for the different hormones. Whereas metabolic routes for hormone syntheses are diverse, their signaling pathways might overlap/interact [7]. This means that simple changes have frequently 
pleiotropic effects, which are difficult to explain at the whole organism level. Therefore, this review focuses on those cases where benefits are clear, as are also the fundament of the biotechnological application.

\section{Gibberellins}

Gibberellins (GAs) are tetracyclic diterpenoid compounds that control diverse aspects of plant growth and development, such as seed germination, stem elongation, leaf expansion and flower and fruit development. More than a hundred of different GAs have been identified in plants and fungi but only a few of them are biologically active, such as $\mathrm{GA}_{1}, \mathrm{GA}_{3}, \mathrm{GA}_{4}$ and $\mathrm{GA}_{7}[8,9]$.

GA biosynthesis occurs in three different compartments: plastids, endoplasmic reticulum and cytosol. In first place, in plastids geranylgeranyl diphosphate (GGDP) acts as a precursor to ent-kaurene, then in the endoplasmic reticulum this ent-kaurene is converted to $\mathrm{GA}_{12}$ by two different cytochrome P450 monooxygenases, and finally $\mathrm{GA}_{12}$ is converted to $\mathrm{GA}_{4}$ through oxidations on C-20 and C-3 by GA 20-oxidase (GA20ox) and GA 3-oxidase (GA3ox) respectively in the cytosol [8, 9].

Cereal crop yields have increased since 1960s because of the introduction of high-yielding varieties of wheat and rice and the application of fertilizers and pesticides. All these changes generated what was called the "Green Revolution" [10]. The problem with the application of fertilizers to traditional varieties became clear quickly for farmers; it did not increase their yield because plants grew too tall and fell over, process known as lodging. What farmers needed were new varieties that gave increase grain yield rather than increased plant biomass with the application of fertilizers [10].

In rice, the dwarf genes originated from a Chinese cultivar, Dee-geo-woo-gen, that was then used to produce the Taichung native 1 (TN-1) and later the IR-8 ("miracle 
rice"). TN-1 and IR-8 have been used also to produce some indica and japonica cultivars. The semi-dwarf phenotype is the result of different alleles of a single recessive gene, $s d l$ [11]. The $s d l$ mutation is recessive and normal height could be restored by GA application, indicating that they were defective in GA production. In 2002, the $s d l$ gene was identified as encoding a GA20ox. Dee-geo-woo-gen rice, possessing the $s d 1$ allele, presents a 383-bp deletion in the GA20ox gene (OsGA20ox2) that introduces a stop codon, producing a truncated enzyme [12]. As GA20ox are members of a gene family and present functional redundancy, loss-of-function GA20ox mutants present only a semi-dwarf phenotype compared with severely GA-deficient plants that are completely dwarfed and sometimes sterile [11].

The rice Tan-Ginbozu ( $\left.d 35^{\text {Tan-Ginbozu }}\right)$ is another example of increased yield by semi-dwarf traits. The $d 35^{\text {Tan-Ginbozu }}$ was first believed to be blocked in the synthesis of ent-kaurene or an earlier reaction. Years later, it was confirmed that the mutation in $d 35^{\text {Tan-Ginbozu }}$ inhibited the activity of ent-kaurene oxidase $(\mathrm{KO})$, that catalyzes the three oxidative steps from ent-kaurene to ent-kaurenioc acid [13].

The study of GA biosynthesis has extended to fruit plants. Some fruit trees can grow very tall if they do it on their own roots, so many of them are grown as scions grafted on to a dwarfing rootstock. These trees are smaller and easier to handle, they also present earlier flowering time and reduced vegetative growth. However, for many crops, rootstocks are not enough and chemical growth retardants are used to prevent excessive vegetative growth. In apple, inhibition of MpGA20oxl by sense or antisense suppression resulted in dwarf plants with much lower levels of $\mathrm{GA}_{1}$. The dwarf phenotype was maintained when the transgenic scions were grafted on to invigorating rootstocks. This technology could be very useful to improve the utilization of rootstocks 
to prevent plants to grow vigorous and to reduce the need for chemical growth retardant application [14].

In the citrus hybrid, Carrizo citrange, used as a rootstock, plants overexpressing sense and antisense CcGA20ox gene produced shorter and taller phenotypes respectively [15]. Plants also showed thorns, organs of citrus in juvenile stages, with abnormal characteristics, they were much longer in sense and shorter in antisense transgenic plants. Internodes cell length was not altered in plants, indicating that in citrus GAs promote cell division rather than cell elongation. When transgenic plants were grafted on wild type rootstocks, the phenotype disappeared, contrary to what was described in apple. This suggests that GA produced in the roots can compensate the deficit of GA in the antisense transgenic aerial part and opens the possibility of using these plants as dwarfing rootstocks [15].

Although the biosynthesis of GA is very well understood since many years ago, the way that plants perceive the hormone and then transmit the signal to the whole plant is still not completely clear. The GA receptor, GID1, was discovered in rice in 2005 [16]. OsGID1 was characterized as a soluble receptor and loss-of-function mutations in the gene were shown to produce plants with a severe dwarf phenotype and loss of GA responsiveness. It was also demonstrated that the OsGID1 protein was able to bind bioactive GAs but not inactive GAs and that OsGID1 interacted with the rice DELLA protein, SLR1. [17, 18].

A few months after the discovery of rice GA receptor, Arabidopsis GID1 orthologs were identified. There are three Arabidopsis GIDl genes, AtGIDIa, $b$ and $c$, and all of them showed GA binding affinity to biologically active GAs. Arabidopsis GID1 receptors show partial redundancy, triple mutant plants show a very severe GAinsensitive phenotype, demonstrating a more important role for GA signaling in 
Arabidopsis growth and development than previously described. As in rice, Arabidopsis GID1s interact with DELLA proteins in a GA-dependent manner [18, 19].

DELLA proteins are repressors of GA signaling and modulate all aspects of GA-induced growth and development in plants [20]. DELLAs belong to the GRAS family of transcriptional regulators, presenting a C-terminal GRAS domain. A unique $\mathrm{N}$-terminal region is what gives name to this family of proteins and is composed of five amino acids, DELLA, a short spacer region and other six amino acids, TVHYNP [17, 20, 21]. This region is known to be essential to normal GA response [22]. DELLA proteins are rapidly degraded in response to GA treatment, and deletion or amino acid substitution in this conserved motif confers GA-insensitive phenotypes [20].

As with biosynthesis mutants, characterization of mutants that are impaired in GA signaling has been crucial to understand the role of GAs in plant development, as well as their targeting for biotechnological achievements. In general, all GA-deficient mutants show a similar phenotype, they are dark-green dwarf plants, defective in leaf expansion, stem elongation and seed germination. In Arabidopsis, a rga null mutation (rga-24) partially suppressed the phenotype of the GA biosynthetic mutant gal-3. The gai mutant was identified because it did not respond to GA application. In contrast to rga-24, gai-t6 null mutation did not suppress the gal-3 phenotype, but in combination with rga-24 completely suppressed the plant defects [10, 23]. The triple mutant (gal-3/ rga-24/ gai-t6) had a slender phenotype but mutant seeds were still non-germinating and mutant plants still showed GA deficient floral defects. This suggests that there must be other genes controlling developmental processes, and these genes are the RGL. A triple null mutant ( $\mathrm{rga} / \mathrm{rgll} / \mathrm{rgl2}$ ) rescued the floral developmental defect and fertility of gal-3 [24]. The gai-1, rgas-17 and rgll mutants all lack 17 amino acids of the DELLA domain, and have a GA-insensitive dwarf phenotype. The deletion in the protein makes 
them constitutive repressors of the GA response; the proteins are not degraded in response to GA as in the wild type [10, 23].

Several mutants with GA-insensitive phenotypes have been identified in other species, like $R h t 1, R h t 2$ and $R h t 3$ in wheat and $d 8$ and $\mathrm{d} 9$ in maize. Many dwarf wheat lines, as Norin 10, were introduced in the USA from Japan. Norin 10 contained the Reduced height genes (Rht), responsible of the high-yielding semi dwarf wheat $[10,11$, 25]. Maize mutant alleles $d 8$ also showed these characteristics. In 1999, Peng et. al [25] demonstrated that Arabidopsis GAI, wheat $R h t-1$ and maize $d 8$ were functional orthologs. They also demonstrated that the mutations of the N-terminal domain of these genes were responsible for the less sensitivity of the proteins to GA [25].

Although all of the DELLA genes were first identified in Arabidopsis and cereals, the study of GA signaling genes in fruit plants is becoming a priority. Parthenocarpy, fruit development without seeds, is a much appreciated characteristic because it ensures high yields in difficult environments with low temperatures or absence of cross pollinators. It has been for many years a main goal in breeding programs of fruit crops. Hormones, particularly auxins and gibberellins, are known to promote fruit development without fertilization. In tomato there is one gene encoding for a DELLA protein, named SIDELLA. Silencing of this gene by antisense technique resulted in slender plants with elongated flower trusses. The fruits were smaller and elongated compared with the wild type. The silencing of this gene also produced pathenocarpic fruits, but this phenomenon was facultative because hand pollination restored wild type fruit phenotype [26].

In grapevine, a dwarf mutant derived from de L1 layer of the apical meristem, produced inflorescences in the shoot instead of the tendrils that are normally formed. The mutated gene was identified as an ortholog of wheat Rht1 and Arabidopsis GAI. 
The formation of inflorescences in the mutant demonstrates that in grapevine, GAs inhibit floral development [27] instead of promoting it as in Arabidopsis [28]. The knowledge of the regulation of the flowering process can be useful to try to control fruit development and therefore to improve the production.

The introduction of the Arabidopsis gai mutant gene in apple, resulted in a clear reduction in stem length, internodes length and node number [29]. This is important since in modern apple production, dwarf trees are commonly used for achieving high production efficiency. However, transgenic plants showed reduced rooting ability. Production of new cultivars or rootstocks with dwarf characteristics has been an important objective for apple breeding.

\section{Auxin}

Since its discovery 70 years ago, the compound indole-3-acetic acid (IAA or auxin) has been the most studied plant hormone. It is known to be involved in almost every aspect of plant growth and development. Depending on the tissue, auxin can promote cell elongation or cell division. The exact mechanisms and sites of auxin biosynthesis remain unclear, but there are two accepted biosynthesis pathways, one dependent and one independent of tryptophan [30].

The first problem to study auxin biosynthesis was the inability to find auxin deficient mutants, since the mutants that presented high levels of free auxin were sterile or had very heterogeneous phenotypes. In addition, it was not possible to determine if the elevated levels of auxin were caused by an effect in auxin biosynthesis or conjugation. In 2001, Zhao, Y. et. al., [31] identified the Arabidopsis yucca mutants, they presented a phenotype characteristic of elevated auxin levels, as long hypocotyls, short roots with long root hairs. They demonstrated that YUCCA is a member of the 
flavin monooxygenase (FMO)-like family that catalyzes a limiting step in Arabidopsis tryptophan-dependent auxin biosynthesis. They also showed that the YUCCA family of proteins is composed in Arabidopsis plants by ten members [31]. There is another auxin biosynthesis mutant in Arabidopsis, the superroot (surl) that presents high levels of both free and conjugated auxin, resulting in auxin related phenotypes. The SURl gene encodes a protein with homology to the tyrosine aminotransferases and may be involved in auxin Trp-dependent and independent biosynthesis pathways [30].

In rice, seven $Y U C C A$-like genes have been identified. In plants overexpressing OsYUCCA1 IAA levels were increased while plants with antisense expression of the gene presented dwarfed shoots and short roots with long root hairs. The results provided evidence for a role of OsYUCCA in auxin biosynthesis as in Arabidopsis [32]. As with GA genes, the modification $O S Y U C C A$ genes in rice can generate the desired dwarf phenotype.

Auxin is known to play an important role in fruit development and ripening both in climacteric and non-climacteric fruits, presenting a peak after ovary fertilization [33]. In strawberry and raspberry, the introduction of DhfH9-iaaM gene fusion, composed of the regulatory region of $\mathrm{DhfH} 9$ gene from snapdragon and the iaaM coding region from Pseudomonas syringae pv savastanoi, that is known to promote auxin synthesis, confer parthenocarpic fruit development to eggplant and tomato and increase fruit production and quality, resulted in an increased number of fruits per plant and also a higher weight and bigger size of the transgenic fruits. The increase in fruit yield reached $180 \%$ in Fragaria $x$ ananassa, the cultivated strawberry, and $140 \%$ in Fragaria vesca, the wild strawberry, while the increase was of $100 \%$ in raspberry. The use of DhfH9-iaaM gene must be considered to improve productivity in these two Rosaceae species [34]. 
The introduction of the DhfH9-iaaM transgene in Thompson Seedless (low shoot fruitfulness) and Silcora (medium shoot fruitfulness) cultivars of grape resulted in an increased number of inflorescences per shoot in transgenic plants for both cultivars, in Thompson Seedless the number was doubled compared to the wild type plants [35].

As what happens with auxin biosynthesis, many aspects of auxin signaling are poorly understood. The auxin receptor TIR1 has recently been identified $[36,37]$. In contrast, auxin regulated transcription is better understood since the past decade. Two big families of transcriptional regulators are known to be involved in this process, the Aux/IAA and ARF (auxin response factors) families. Auxin, after its binding to TIR1, promotes the interaction between Aux/IAA proteins and the ubiquitin protein ligase $\mathrm{SCF}^{\mathrm{TIR} 1}$, stimulating the degradation of Aux/IAA proteins. Actually, the auxin receptor TIR1 is part of the $\mathrm{SCF}^{\mathrm{TIR} 1}$ ubiquitin ligase complex and binds auxin directly. The degradation of Aux/IAA proteins allows ARFs to bind to auxin regulated genes, activating or repressing their transcription [30].

In tomato, the diageotropica (dgt) mutant was identified as being defective in some auxin-mediated responses. It was demonstrated that the mutant presented an inhibition of the auxin induction of the only tomato Aux/IAA gene identified at that moment, LeIAA [38]. Years later, ten other Aux/IAA genes were identified in tomato, some of them also showed a reduced auxin stimulation of gene expression [39]. The inhibition of SIIAA9 produced plants with simple leaves instead of the compound leaves of the wild type, and most importantly it induced fruit parthenocarpy. Despite their parthenocarpic character, fruits presented normal size, skin color and flesh consistency and they showed no change in ripening process. SIIAA9 antisense lines were auxin hypersensitive, presenting hypocotyls elongation, reduced apical dominance and 
increased leaf vascularization [40]. Later, it was demonstrated that a single-base deletion mutation in SIIAA9 gene caused the tomato mutant phenotype [41].

In potato, auxins are known to play an important role in tuber development. Endogenous auxin levels are high prior and during stolon swelling and after that they start to decrease gradually. The first potato Aux/IAA gene identified, named StIAA, was shown to be induced in potato tubers after fungal infection, but it was not clear if the infection by itself caused the accumulation of $A u x / I A A$ mRNAs or if it was the result of other signals released by the fungus or the plant [42]. Another $A u x / I A A$ gene was identified in potato, StIAA2. Transgenic plants overexpressing StIAA2 did not show any visible phenotype; in contrast, transgenic plants inhibiting the gene expression presented several dramatic defects. Plants were much taller, they contained two to three more internodes, presented petiole hyponasty and extreme curvature of growing leaf primordia in the shoot apex. These phenotypes are both common and unique to the ones found in other plants, like Arabidopsis and tomato, and evidenced the importance of studying the function of $A u x / I A A$ genes individually, and in different plant species [43]. In addition, overlapping functions among different Aux/IAA family members must be considered when affording a biotechnological benefit of modifying a single gene.

$A R F$ genes are expressed in a wide range of tissues and organs. Screens in Arabidopsis T-DNA insertion mutations have identified many ARF mutants, but most of them did not show a distinctive phenotype. That is not the case with ARF double mutants that usually present a clear phenotype, as delayed flower maturation, reduced fertility, reduced lateral root number, root cap defects and abnormal root gravitropism [44]. A mutation in the coding region of AtARF8 resulted in the production of parthenocarpic fruits in Arabidopsis [45]. This was also found to be the case in tomato, in which the expression of Atarf8-4, an aberrant form of the gene, in transgenic tomato 


\section{Ethylene}

Ethylene is a gaseous hormone that regulates many aspects of plant growth and development, including seed germination, root and stem elongation, root hair development, root nodulation, flower senescence, abscission, sex determination, fruit ripening, programmed cell death, responses to biotic and abiotic stresses, gravitropism, and interaction between roots and rhyzosphere [48, 49].

Ethylene is produced in plants from $S$-adenosyl-methionine (SAM), which is first converted in 1-aminocyclopropane-1-carboxylate (ACC) by the action of ACC synthase (ACS), and then oxidized to ethylene by the ACC oxidase (ACO). Both ACC synthase and ACC oxidase activities are encoded by multi-gene families, and the transcription of the different genes is induced under different environmental and physiological conditions $[50,51]$.

Ethylene is perceived by a family of membrane-localized receptors that are homologous to bacterial two-component histidine kinases. The number of isoforms as well as the expression profiles varies within the species. For instance, Arabidopsis harbors five ethylene receptors, ETHYLENE RECEPTOR1 (ETR1), ETR2, ETHYLENE INSENSITIVE4 (EIN4), ETHYLENE RESPONSE SENSOR1 (ERS1), 
and ERS2; compared to the six of tomato, LeETR1, LeETR2, NEVER RIPE (NR), LeETR4, LeETR5, and LeETR6; but ethylene-binding studies indicate similar ethylene affinities for all Arabidopsis and tomato receptor proteins [52]. In Arabidopsis, ethylene receptors play a negative role in the ethylene pathway [53]. It has been found that the REVERSION-TO-ETHYLENE-SENSITIVITY1 (RTE1) protein genetically interacts with ethylene receptors for the regulation of the ethylene response [54]. In the absence of ethylene, the receptors are continuously stimulating CONSTITUTIVE TRIPLE RESPONSE1, CTR1, which is a Ser/Thr kinase, and in this way, inhibits the rest of the downstream components of the pathway. When ethylene binds to the receptors, the MAPK cascade is released and results in the activation of EIN2, a positive key regulator in the ethylene transduction pathway, which transmits the signal to the EIN3/EIL family of transcription factors $[53,55]$. At the end of the pathway are the ethylene inducible genes which expression is under the control of the ethylene response transcription factors (ERF). ERF-type transcription factors are specific to plants and belong to the large AP2/ERF family. ERFs provide a control point for integration of multiple signals and for diversification of ethylene responses [56].

The role of ethylene in promoting fruit ripening and flower senescence provided a commercial incentive for early, successful approaches to down-regulation of its production. It is well described that the ripening of climacteric fruits is initiated by a peak of autocatalytic production of ethylene. It is assumed that control of ethylene production at the late stages of ripening will delay the processes occurring at this stage, and consequently will extend the shelf life of the fruit. Tomato has been the model plant for genetic manipulation, although similar strategies have been used in melon and apple. In terms of synthesis, genes encoding for the biosynthetic steps as ACC synthase and ACC oxidase have been silenced, by both antisense technology and RNAi (RNA 
interference). Antisense inhibition of LeACS2, which also down-regulated LeACS4, reduced ripening-related synthesis of ethylene to $0.1 \%$ of control fruit. The antisense fruit displayed an abnormal pattern of ripening such as reduced lycopene accumulation, delayed softening and a much reduced climacteric peak [57]. This antisense strategy has also been used in apple transformed with the antisense versions of the apple ACC synthase and ACC oxidase with the aim of studying the role of ethylene in apple ripening [58]. They observed very low levels of ethylene synthesis in three year old apple trees grown in the field, and hence fruit that ripened more slowly. One side effect of this strategy was a decrease in the concentration of enzymes responsible for the formation of flavour esters, an effect that may adversely affect consumer acceptance. RNAi strategy has also been used to silence ACO, these transgenic tomato plants produced fruit that released only traces of ethylene and had a shelf life of more than 120 days [59]. In addition, to interfere with the endogenous synthesis of ethylene the heterologous expression of ACC deaminase, cloned from soil bacteria, has been employed. Effectively, the microbial enzyme ACC deaminase converts ACC to ammonia and $\alpha$-ketobutyrate, both of which are further metabolized. By inserting the ACC deaminase gene into tomato plants under the control of the CaMV 35S promoter, fruits with delayed ripening were readily produced [60]. No other significant phenotypic differences were observed between plants with high levels of ACC deaminase activity and nontransformed plants.

Another strategy used to interfere with the ethylene action has been the use of the mutated ethylene receptor from Arabidopsis etrl-1. This is a dominant mutation that confers ethylene insensitivity when expressed in heterologous plant species. Thus, overexpression of etrl-1 has been used to produce transgenic plants with diminished sensitivity to the hormone [61]. Seedling growth, flower senescence, flower abscission, 
and fruit ripening were all affected by the presence of the etrl-1 transgene in both petunia and tomato plants. Regarding other receptors, NR was the first ethylene receptor discovered in tomato. The $n r$ tomato mutant shows global and total ethylene insensitivity [62]. As NR and LeETR4 genes are up-regulated during ripening, they have both been targeted for antisense experiments. Antisense repression of the mutant NR gene in the Nr background produced fruit that ripened normally indicating that the NR ethylene receptor is not required for ripening and confirming the receptor inhibition model of ethylene signaling [63]. By opposite, it is becoming apparent that LeETR4 plays an important role in ripening. Down regulation of LeETR4 produces an ethylene hypersensitive phenotype that includes accelerated ripening [64], whereas in Arabidopsis increased ethylene sensitivity is not observed until three receptors have been knocked out [65]. The tomato dominant mutant Green ripe $(G r)$ is specifically defective in fruit ethylene responses. It has been found that the mutation is the consequence of a deletion in the 5'flanking region of the gene and causes ectopic expression of GR [66]. Interestingly, GR and RTE1 are members of the same protein family, and GR could achieve the appearance of tissue-specific function of the different ethylene receptors if it interacts with specific receptors [67].

The process of flower senescence, with the consequence of flower wilting and decay, is triggered in many plant species by ethylene. Thus, commercial plants of carnation, begonia, and torenia have been produced with an antisense ACC oxidase construct. In all the cases there was a dramatic decrease of endogenous ethylene production and the benefit of extended vase life of the cut flowers [55]. Also, ethyleneinsensitive carnation flowers were produced after transformation with the Arababidopsis etrl-1 gene. Transgenic carnation cut flowers had three times the vase 
life of non-transformed flowers and lasted up to 16 days, which is longer than flowers treated with either inhibitors of ethylene biosynthesis or ethylene antagonists $[68,69]$.

It has been established that ethylene response factor (ERF) proteins play important regulatory roles in plant response to abiotic and biotic stresses. Among abiotic stresses, drought is the most devastating constraint to crop productivity. Tobacco plants overexpressing JERF3, a tomato ERF protein, showed an enhanced resistance to drought, salinity and freezing [70]. Enhanced tolerance to drought and high salinity was also observed in rice plants overexpressing TERF1, another tomato ERF protein [71]. Regarding biotic stress, another field of biotechnological application of the control of ethylene production is in the plant defense system. Ethylene involvement in the plant defense is complex, and commonly coordinated to other plant hormones. Thus, it is known that ethylene production might be an early response of plants to pathogen attack, being associated to defense reaction, but it is also known that some pathogenic fungi and bacteria are capable of producing ethylene as a virulence factor. This contradictory role played by ethylene has resulted in quite variable effects of the diminution of ethylene production and sensitivity in the plant sensitivity to pathogens [72]. For example, tobacco plants transformed with the etrl-1 mutant gene from Arabidopsis are insensitive to ethylene and develop symptoms of wilting and stem rot when grown in nonautoclaved soil [73]. Regarding the signaling cascade, the Arabidopsis mutant ein2, impaired in ethylene signal transmission, exhibits increased susceptibility to the necrotrophic fungus $B$. cinerea and the necrotrophic bacterium Erwinia carotovora but shows no alteration in susceptibility to the biotrophic Oomycete $H$. parasitica and the biotrophic bacterium $P$. syringae pv tomato. Similar phenotypic effects, plants more resistant/susceptible to some pathogen species with no effect to other pathogen species, were obtained following other strategies, like the overexpression of some Arabidopsis, 
tobacco or tomato ERF genes [74]. In general, these results indicate that ethylene and ERF-like transcription factors are involved in defense responses of various plant species, but that their effect on disease resistance depends on the specific plantpathogen interaction. However, it appears as an area for future developments of genetic strategy, transgenic or mutants, for improving plant response to pathogens.

Success has been variable, mainly due to two facts. First is that usually endogenous enzymes are encoded by gene families, being the transcription of the various members organ-, tissue-, and developmental-dependent. This makes unpredictable the final result of the genetic engineering strategy. Second, which is related to the first, is that abolition of ethylene production in the whole plant frequently have deleterious effects. Best solution to these shortcomings has been the use of specific promoters [69].

\section{Cytokinins}

Cytokinin (CK) was initially discovered as the hormone that promotes cell division; it is now known to influence many aspects of plant growth and development [75]. Cytokinins (CKs) are a structurally diverse group of biological molecules whose chemistry has been extensively studied. However, some aspects of their metabolism and signaling pathways are still undefined. The natural cytokinins are adenine derivatives that can be classified by the configuration of their N6-side chain as isoprenoid or aromatic cytokinins [75]. Biotechnological applications in relation to this hormone have rested on the possibility of changing their endogenous level in a tissue/organ specific manner. Local levels of CKs are controlled by synthesis, transport, inactivation, and oxidation. Among these, synthesis and oxidation have been the targets for biotechnological plant improvement. 
In the synthesis pathway there is an ATP/ADP isopentenyltransferase (IPT) gene that encodes for a rate-limiting step. In Arabidopsis seven IPT genes have been identified, being the promoters of four of them suppressed by CKs [76]. The only IPTencoding gene known in Petunia hybrida [77] has been used to modify the internal level of CKs. This has been performed in potato where CKs are known to influence tuber initiation, growth and dormancy. Potato plants cultured in vitro showed a significantly increased tuber biomass after cytokinin application [78]. The Sho gene, from Petunia hybrida, encodes an enzyme for cytokinin synthesis [79]. Moderate expression of the Sho gene in potato produced and enhanced shoot production, delayed tuber formation with significant reduction in tuber size, and inhibition of tuber dormancy [79]. In general, stimulation of shoot and stolon development can be beneficial, jointly with the reduction of dormancy, for enhanced tuber production. However, as occurs with other transgenic plants, there are deleterious effects derived from ectopic expression of the transgene. This must be eventually overcome with the use of tissue/stage-specific promoters, as above indicated.

In the catabolic pathway there is a step catalyzed by a cytokinin oxidase/dehydrogenase enzyme (CKX) [75]. This enzyme irreversibly degrades CKs by cleavage of the unsaturated N6-isoprenoid side chain. This step plays a main role in controlling CK levels in plants. Selection of the corresponding gene as a target for genetic engineering was based on previous studies aimed to characterize in many crops, including rice, quantitative trait loci (QTLs) responsible for grain number, and eventually for higher yield. Grain number is an important trait that contributes directly to crop yield. A QTL that increases grain number in rice, Gnla, was identified. High resolution mapping of this Gnla identified as a possible candidate gene the one with a predicted open reading frame with high similarity to cytokinin oxidase/dehydrogenase 
$(O s C K X 2)$ [80]. This was further confirmed by producing transgenic rice plants expressing different levels of $O s C K X 2$ and examining the grain yield. Lines with two copies of the sense strand of $O s C K X 2$ showed reduced grain number compared to the control, whereas lines with antisense strands, which had reduced levels of expression, showed higher grain number [80]. Grain number jointly with plant height is an important trait that directly contributes to grain productivity. Thus, the manipulation of OsCKX2 in rice is relevant since food shortage still remains as one of the most serious problems in this century. It is envisaged that crop grain production will need to increase by $50 \%$ by 2025 to meet the expanding food demands of the growing world population [81].

\section{Brassinosteroids}

Brassinosteroids (BRs) constitute another class of plant hormones that participate in multiple plant physiological processes like cell division, cell elongation, vascular differentiation, root growth inhibition, and ethylene synthesis. Currently 42 brassinosteroid metabolites and conjugates are known [82], among them the most physiologically active is Brassinolide (BL). Metabolic pathways for BRs biosynthesis might vary depending upon the plant species, the developmental stage, and the BR structure. Two categories of changes have been reported in BRs metabolism: 1) structural changes of the steroidal skeleton; and 2) structural changes in the side chain. The most common modification in the side chain include hydroxylation and side chain cleavage. Less common modifications include dehydrogenation, glycosylation and demethylation [82]. The synthesis of the steroidal skeleton starts from an initial precursor, campesterol, and de BR intermediates undergo a series of hydroxylations, reductions and epimerization, and a oxidation leading to the brassinolide (BL), the most 
biologically active. The signaling pathway is being characterized. The receptor BRI1 was identified by positional cloning in a mutant of Arabidopsis (bril) insensitive to brassinosteroids [83].

The importance of brassinosteroids in cell elongation has generated interest in manipulating their levels. It was reported that exogenous application of brassinosteroids to a number of vegetables increased yields [84]. Recently, main interest has been in rice where they are known to influence both plant height and leaf erectness [85]. Erect leaves enhance light capture for photosynthesis, what allows more dense plantings and higher nitrogen storage. The result is an increase in yield.

In the screening of a mutant rice population, generated by $\gamma$-ray irradiation, retrotransposon-mediated, or chemical mutagenesis, a mutant was isolated, osdwarf4-1, with erect leaves but without abnormal leaf, flower or grain morphology. The gene was finally identified as OsDWARF4 after characterizing the site of insertion of the retrotransposon [86]. This gene is homologue of the DWARF4 gene from Arabidopsis that encodes a cytochrome P450 that catalyzes the C-22 hydroxylation rate limiting step of brassinolide biosynthesis [87].

Most plant genes for brassinosteroid biosynthesis exist as single copies, however in rice there are two genes encoding the P450 C-22 hydroxylase, OsDWARF4L1 that acts during shoot elongation and reproductive development, and the OsDWARF4 gene that controls leaf inclination. Thus the osdwarf4-1 mutant displayed increased erectness of the leaves, without the severe phenotype of the double mutant osdwarf41/osdwarf4l1 plants. Small field trials involving the wild type and the osdwarf4-1 mutant revealed that yield was higher for mutants, being the difference higher with the increase of density of planting and the amount of nitrogen fertilizer [86]. Biomass production of the osdwarf4-1 plants was increased nearly $40 \%$ as compared with the 
wild type plants. Under normal or dense planting conditions the erect leaves of the mutants increased photosynthetic rates and as result the plants were more productive.

Table 1 shows some prominent examples of biotechnological applications derived from changes either in the hormone levels or the signaling pathways.

\section{Future prospects}

It is accepted that rational approach to improve crop quality depends on a better understanding of plant biology, in this case of hormone biosynthesis and signaling. Genomic projects have deciphered the sequences of tens of thousands of genes in plant genomes, but it is needed to know which genes control the quality traits of the crops by their involvement in hormone action. The functional genomics tools are being used for this task that will pave the way for biotechnological applications. Among these, those related to reverse genetics are becoming more important. We consider here the main advantages and disadvantages of two of them: the preparation of transgenic plants and the generation of chemical mutants.

Field growth of transgenic crops for commercial production has been continuously increasing to reach values over 120 M of hectares by 2007 (www.isaaa.org/resources/publications). However, most of them are restricted to few species (soybean, maize, cotton, and canola) and few traits (herbicide and insect resistance). In terms of hormone balance one of the most conspicuous events was performed in rice, where tissue-specific expression of the GA2ox gene caused a dwarf phenotype without affecting grain yield. Ectopic expression of the transgene, with the consequent pleiotropic effect, was avoided by using the promoter of another rice biosynthetic gene (OsGA3oxl) [88]. The need of tissue/developmental-specific promoters is a great challenge for the future development of transgenic plants that 
becomes even more important when hormone actions are targeted. Limitations to have access to these promoters are: 1) lack of characterization of 5 ' regulatory regions; 2) lack of knowledge on the rules for promoter engineering; 3) unavailability of efficient systems for gene targeting/homologous recombination in plants [89].

Future developments of commercially attractive transgenic plants would be probably restricted to main crops, like cereals and some legumes, improved in traits with benefits for developing countries. Rejection by most European countries of the technology of genetic modification, known as GMO, appears as a great shortcoming for future development of new transgenic plants, especially in quality traits appreciated by the consumers of the developed countries.

Most transgenic plants commonly present a complete loss of function, or constitutive gain of function, phenotypes that make them unacceptable as commercial crops [11]. However, it should be reminded that there were two alleles in two species that were critical to bring about the Green Revolution [10]. This indicates that the alleles that cause just a moderate variation in the physiology of the plant are the most important for the development of new commercial varieties. Since natural variation for new alleles is limited, once again chemical mutagenesis is being used to look for new improvements in plant performance. The use of the technical approach known as targeted induced local lesions in genomes (TILLING) [90] will facilitate the job. Using this technique, point mutations of selected genes can be produced and screened for their phenotypic effect. There are examples where allelic variants are produced and screened by TILLING to generate the desired phenotype [91]. The possibility of modifying multiple alleles with non GMO technology will become more realistic in the future, as the genome sequencing projects and the refinement of what is known as system biology will increase the predictive value of specific genetic changes. 


\section{Ackonowledgements}

The authors are financially supported by the Grant BIO2007-67509-C02-01 (Ministerio de Educación y Ciencia, Spain). 


\section{References}

[1] Galston, A. W., Davies, P. J. Hormonal regulation in higher plants. Science 1969, 163, 1288-1297.

[2] Sakamoto, T. Phytohormones and rice crop yield: strategies and opportunities for genetic improvement. Transgenic Res. 2006, 15, 399-404.

[3] McSteen, P., Zhao, Y. Plant hormones and signaling: common themes and new developments. Dev. Cell 2008, 14, 467-473.

[4] Spartz, A. K., Gray, W. M. Plant hormone receptors: new perceptions. Genes Dev. 2008, $22,2139-2148$.

[5] Gómez-Roldán, V., Fermas, S., Brewer, P. B., Puech-Pagès, V. et al. Strigolactone inhibition of shoot branching. Nature 2008, 455, 189-194.

[6] Umehara, M.,, Hanada, A., Yoshida, S., Akiyama, K., et al. Inhibition of shoot branching by new terpenoid plant hormones. Nature 2008, 455, 195-201.

[7] Kepinski, S. Integrating hormone signaling and patterning mechanisms in plant development. Curr. Opin. Plant Biol. 2006, 9, 28-34.

[8] Olszewski, N., Sun, T., Gubler, F. Gibberellin signaling: Biosynthesis, catabolism and response pathways. Plant Cell 2002, 14, S-61-S80.

[9] Yamaguchi, S. Gibberellin metabolism and its regulation. Annu. Rev. Plant Biol. 2008, 59, $225-251$.

[10] Silverstone, A., Sun, T. Gibberellins and the green revolution. Trends Plant Sci. 2000, 5, 1-2.

[11] Hedden P. The genes of the green revolution. Trends Genet. 2003, 19, 5-9.

[12] Sasaki, A., Ashikari, M., Ueguchi-Tanaka, M., Itoh, H. et al. A mutant gibberellinsynthesis gene in rice. Nature 2002, 416, 701-702. 
[13] Itoh, H., Tatsumi, T., Sakamoto, T., Otomo, K. et al. A rice semi-dwarf gene, TanGinbozu (D35), encodes the gibberellin biosynthesis enzyme, ent-kaurene oxidase. Plant Mol. Biol. 2004, 54, 533-547.

[14] Bulley, S. M., Wilson, F. M., Hedden, P., Philips, A. L. et al. Modification of gibberellin biosynthesis in the grafted apple scion allows control of tree height independent of the rootstock. Plant Biotechnol. J. 2005, 3, 215-223.

[15] Fagoaga, C., Tadeo, F. R., Iglesias, D. J., Huerta, L. et al. Engineering of gibberellin levels in citrus by sense and antisense overexpression of a GA 20-oxidase gene modifies plant architecture. J. Exp. Bot. 2007, 58, 1407-1420.

[16] Ueguchi-Tanaka, M., Ashikari, M., Nakajima, M., Itoh, H. et al. Gibberellin insensitive dwarf1 encodes a soluble receptor for gibberellin. Nature 2005, 437, 693-698.

[17] Ueguchi-Tanaka, M., Nakajima, M., Katoh, E., Ohimiya, H. et al. Molecular interactions of a soluble gibberellin receptor, GID1, with a rice DELLA protein, SLR1, and gibberellin. Plant Cell 2007, 19, 2140-2155.

[18] Nakajima, M., Shimada, A., Takashi, Y., Kim, Y. et al. Identification and characterization of Arabidopsis gibberellin receptors. Plant J. 2006, 46, 880-889.

[19] Griffiths, J., Murase, K., Rieu, I., Zentella, R. et al. Genetic characterization and functional analysis of the GID1 receptors in Arabidopsis. Plant Cell 2006, 18, 33993414.

[20] Zentella, R., Zhang, Z., Park, M., Thomas, S. et al. Global analysis of DELLA direct targets in early gibberellin signaling in Arabidopsis. Plant Cell 2007, 19, 3037-3057.

[21] Achard, P., Liao, L., Jiang, C., Desnos, T. et al. DELlAs contribute to plant photomorphogenesis. Plant Physiol. 2007, 143, 1163-1172.

[22] Swain, S. M., Singh, D. P. Tall tales from sly dwarves: novel functions of gibberellins in plant development. Trends Plant Sci. 2005, 10, 123-129. 
[23] Thomas, S., Sun, T. Update in gibberellin signaling. A tale of the tall and the short. Plant Physiol. 2004, 135, 668-676.

[24] Cheng, H., Qin, L., Lee, S., Fu, X. et al. Gibberellin regulates Arabidopsis floral development via suppression of DELLA protein function. Development 2004, 131, $1055-1064$.

[25] Peng, J., Richards, D. E., Hartley, N. M., Murphy, G. P. et al. Green revolution genes encode mutant gibberellin response modulators. Nature 1999, 400, 256-261.

[26] Martí, C., Orzáez, D., Ellul, P., Moreno, V. et al. Silencing of DELLA induces facultative parthenocarpy in tomato fruits. Plant J. 2007, 52, 865-876.

[27] Boss, P., Thomas, M. Association of dwarfism and floral induction with a grape "green revolution" mutation. Nature 2002, 416, 847-850.

[28] Blázquez, M., Weigel, D. Integration of floral inductive signals in Arabidopsis. Nature $2000,404,889-892$.

[29] Zhu, L. H., Li, X. Y., Welander, E. M. Overexpression of the Arabidopsis gai gene in apple significantly reduces plant size. Plant Cell Rep. 2008, 27, 289-296.

[30] Benjamins, R., Scheres, B. Auxin: the looping star in plant development. Annu. Rev. Plant Biol. 2008, 59: 443-465.

[31] Zhao, Y., Christensen, S. K., Fankhauser, C., Cashman, J. R. et al. A role for flavin monooxygenase-like enzymes in auxin biosynthesis. Science 2001, 291, 306-309.

[32] Yamamoto, Y., Kamiya, N., Morinaka, Y., Matsuoka, M. et al. Auxin biosynthesis by the YUCCA genes in rice. Plant Physiol. 2007, 143, 1362-1371.

[33] Gillaspy, G., Ben-David, H., Gruissem, W. Fruits: A developmental perspective. Plant Cell 1993, 5, 1439-1451. 
[34] Mezzetti, B., Landi, L., Pandolfini, T., Spena, A. The defH9-iaaM auxin-synthesizing gene increases plant fecundity and fruit production in strawberry and raspberry. $B M C$ biotechnol. 2004, 4, 4-14.

[35] Costantini, E., Landi, L., Silverstroni, O., Pandolfini, T. et al. Auxin synthesis-encoding transgene enhances grape fecundity. Plant Physiol. 2007, 143, 1689-1694.

[36] Dharmasiri, N., Dharmasiri, S., Estelle, M. The F-box protein TIR1 is an auxin receptor. Nature 2005, 435: 441-445.

[37] Kepinski, S., Leyser, O. The Arabidopsis F-box protein TIR1 is an auxin receptor. Nature 2005, 435: 446-451.

[38] Mito, N., Bennett, A. B. The diageotropica mutation and synthetic auxins differentially affect the expression of auxin-regulated genes in tomato. Plant Physiol. 1995, 109, 293297.

[39] Nebenführ, A., White, T. J., Lomax, T. L. The diageotropica mutation alters auxin induction of a subset of the Aux/IAA gene family in tomato. Plant Mol. Biol. 2000, 44, 73-84.

[40] Wang, H., Jones, B., Li, Z., Frasse, P. et al. The tomato Aux/IAA transcription factor IAA9 is involved in fruit development and leaf morphology. Plant Cell 2005, 17, 26762692.

[41] Zhang, J., Cheng, R., Xiao, J., Qian, C. et al. A single-base deletion mutation in SlIAA9 gene causes tomato (Solanum lycospersicum) entire mutant. J. Plant Res. 2007, 120, 671-678.

[42] Zanetti, M. E., Terrile, M., Godoy, A. V., San Segundo, B. et al. Molecular characterization of a potato cDNA encoding a stress regulated Aux/IAA protein. Plant Physiol. Biochem. 2003, 41, 755-760. 
[43] Kloosterman, B., Visser, R. G. F., Bachem, C. W. B. Isolation and characterization of a novel potato Auxin/Indole-3-Acetic Acid family member (StIAA2) that is involved in petiole hyponasty and shoot morphogenesis. Plant Physiol. Biochem. 2006, 44, 766775.

[44] Guilfoyle, T. J., Hagen, G. Auxin response factors. Curr. Opin. Plant Biol. 2007, 10, 453460.

[45] Goetz, M., Vivian-Smith, A., Jonson, S. D., Koltunow, A. M. Auxin response factor 8 is a negative regulator of fruit initiation in Arabidopsis. Plant Cell 2006, 18, 1873-1886.

[46] Goetz, M., Hooper, L. C., Johnson, S. D., Carlyle Macedo Rodrigus, J. et al. Expression of aberrant forms of auxin response factor 8 stimulates parthenocarpy in Arabidopsis and tomato. Plant Physiol. 2007, 145, 351-366.

[47] Jones, B., Frasse, P., Olmos, E., Zegzouti, H. et al. Down-regulation of DR12, an auxinresponse-factor homolog, in the tomato results in a pleiotropic phenotype including dark green and blotchy ripening fruit. Plant J. 2002, 32, 603-613.

[48] Stepanova, A. N., Ecker, J. R. Ethylene signaling: from mutants to molecules. Curr. Opin. Plant Biol. 2000, 3, 353-360

[49] Delseny, M., Charng, Y., Wang, K.L. Ethylene biology: a foreword. Plant Sci. 2008, 175: 1.

[50] Andersson-Gunneras, S., Hellgren, J.M., Björklund, S., Regan, S., et al. Asymmetric expression of a poplar ACC oxidase controls ethylene production during gravitational induction of tension wood. Plant J. 2003, 34, 339-349.

[51] Wang, N.N., Shih, M.C., Li, N. The GUS reporter-aided analysis of the promoter activities of Arabidopsis ACC synthase genes AtACS4, AtACS5, and AtACS7 induced by hormones and stresses. J. Exp. Bot. 2005, 56, 909-920. 
[52] Giovannoni, J. J. Fruit ripening mutants yield insights into ripening control. Curr. Opin. Plant Biol. 2007, 10, 283-289.

[53] Guo, H., Ecker, J. R. The ethylene signaling pathway: new insights. Curr. Opin. Plant Biol. 2004, 7, 40-49.

[54] Resnick, J.S., Wen, C.K., Shockey, J.A., Chang, C. REVERSION-TO-ETHYLENE SENSITIVITY1, a conserved gene that regulates ethylene receptor function in Arabidopsis. Proc. Natl. Acad. Sci. USA 2006, 103, 7917-7922.

[55] Czarny, J. C., Grichko, V. P., Glick, B. R. Genetic modulation of ethylene biosynthesis and signaling in plants. Biotechnol. Adv. 2006, 24, 410-419.

[56] Fujimoto S. Y., Ohta M., Usui A., Shinshi H. et al. Arabidopsis ethylene-responsive element binding factors act as transcriptional activators or repressors of GCC boxmediated gene expression. Plant Cell 2000, 12, 393- 404.

[57] Oeller, P.W., Lu, M.W., Taylor, L.P., Pike, D.A., Theologis, A. Reversible inhibition of tomato fruit senescence by antisense RNA. Science 1991, 254, 437-439.

[58] Dandekar AM, Teo G, Defilippi BG, Uratsu SL, et al. Effect of down-regulation of ethylene biosynthesis on fruit flavor complex in apple fruit. Transgenic Res 2004, 13, $373-384$.

[59] Xiong AS, Yao QH, Peng RH, Li X, et al. Different effects on ACC oxidase gene silencing triggered by RNA interference in transgenic tomato. Plant Cell Rep. 2005, 23, 639-646.

[60] Klee HJ, Hayford MB, Kretzmer KA, Barry GF, et al. Control of ethylene synthesis by expression of a bacterial enzyme in transgenic tomato plants. Plant Cell 1991, 3, 11871193. 
[61] Wilkinson, J. Q., Lanahan, M.B., Clark, D.G., Bleeker, A. B. et al. A dominant mutant receptor for Arabidopsis confers ethylene insensitivity in heterologous plants. Nat. Biotechnol. 1997, 15, 444-447.

[62] Lanahan, M., Yen, H., Giovannoni, J., Klee, H.J. The Never-ripe mutation blocks ethylene perception in tomato. Plant Cell 1994, 6, 521-530.

[63] Hackett, R.M., Ho, C.W., Lin, Z., Foote, H.C., et al. Antisense inhibition of the $\mathrm{Nr}$ gene restores normal ripening to the tomato Never-ripe mutant, consistent with the ethylene receptor-inhibition model. Plant Physiol. 2000, 124, 1079-1086.

[64] Tieman, D.M., Taylor, M.G., Ciardi, J.A., Klee, H.J. The tomato ethylene receptors NR and LeETR4 are negative regulators of ethylene response and exhibit functional compensation within a multigene family. Proc. Natl. Acad. Sci. USA ,2000, 97, 56635668.

[65] Hua, J., Meyerowitz, E.M.. Ethylene responses are negatively regulated by a receptor gene family in Arabidopsis thaliana. Cell 1998, 94, 261-271.

[66] Barry, C.S., Giovannoni, J.J. Ripening in the tomato Green-ripe mutant is inhibited by ectopic expression of a protein that disrupts ethylene signaling. Proc. Natl. Acad. Sci. USA 2006, 103, 7923-7928.

[67] Klee H. Highly conserved proteins that modify plant ethylene responses. Proc. Natl. Acad. Sci. USA 2006, 103, 7537-7538.

[68] Bovy, A.G., Angenet, G.C., Dons, H.J.M., van Altvorst, A.C. Heterologous expression of the Arabidopsis etr1-1 allele inhibits the senescence of carnation flowers. Mol. Breed. 1999, 5, 301-308.

[69] Baudinette, S. C., Stevenson, T. W., Savin, K. W. Isolation and characterization of the carnation floral-specific MADS box gene, CMB2. Plant Sci. 2000, 155, 123-131. 
[70] Wu, L., Zhang, Z., Zhang, H., Wang, X., Huang, R. Transcriptional modulation of ERF protein JERF3 in the oxidative stress response enhances tolerance of tobacco seedlings to salt, drought and freezing. Plant Physiol 2008, DOI: 10.1104/pp.108.126813

[71] Gao, S., Zhang, H., Tian, Y., Li, F., et al. Expression of TERF1 in rice regulates expression of stress-responsive genes and enhances tolerance to drought and highsalinity. Plant Cell Rep. 2008, 27, 1787-1795.

[72] van Loon, L. C., Geraats, B. P. J., Linhorst, H. J. M. Ethylene as a modulator of disease resistance in plants. Trends Plant Sci. 2006, 11, 184-191.

[73] Geraats, B.P., Bakker, P.A., Lawrence, C.B., Achuo, E.A., et al. Ethylene-insensitive tobacco shows differentially altered susceptibility to different pathogens. Phytopathology. 2003, 93, 813-821.

[74] Broekaert, W.F., Delauré, S,L., De Bolle, M.F.C., Cammue, B.P.A. The role of ethylene in host-pathogen interactions. Annu. Rev. Phytopathol. 2006, 44, 393-416.

[75] Mok, D. W. S., Mok, M. C. Cytokinin metabolism and action. Annu. Rev. Plant Physiol. Plant Mol. Biol. 2001, 52, 89-118.

[76] Miyawaki, K., Matsumoto-Kitano, M., Kakimoto, T. Expression of cytokinin biosynthetic isopentenyltransferase genes in Arabidopsis: tissue specificity and regulation by auxin, cytokinin, and nitrate. Plant J. 2004, 37, 128-138.

[77] Zubko, E., Meyer, P. A natural antisense transcript of the Petunia hybrida Sho gene suggests a role for an antisense mechanism in cytokinin regulation. Plant J. 2007, 52, 1131-1139.

[78] Romanov, G.A., Aksenova, N.P., Konstantinova, T.N., Golyanovskaye, S.A. et al. Effect of indole-3-acetic acid and kinetin in tuberisation parameters of different cultivars and transgenic lines of potato in vitro. Plant Growth Regul. 2000, 32, 245-251. 
[79] Zubko E., Macháĉková I., Malbeck J., Meyer P. Modification of cytokinin levels in potato via expression of the Petunia hybrida Sho gene. Transgenic Res. 2005, 14, 615-618.

[80] Ashikari, M., Sakakibara, H., Lin, S., Yamamoto, T. et al. Cytokinin oxidase regulates rice grain production. Science 2005, 309, 741-745.

[81] Khush, G.S. Challenges for meeting the global food and nutrient needs in the new millennium. Proc. Nutrit. Soc. 2001, 60, 15-26.

[82] Bajguz, A. Metabolism of brassinosteroids in plants. Plant Physiol. Biochem. 2007, 45, 95-107.

[83] Wang, Z. Y., Seto, H., Fujioka, S., Yoshida, S. et al. BRI1 is a critical component of a plasma-membrane receptor for plant steroids. Nature 2001, 410 380-383.

[84] Maugh T. H. New chemicals promise larger crops. Science 1981, 312, 33-34.

[85] Sakamoto, T., Matsouka, M. Generating high-yielding varieties by genetic manipulation of plant architecture. Curr. Opin. Plant Biol. 2004, 15, 144-147.

[86] Sakamoto, T., Morinka, Y., Ohnishi, T., Sunohara, H. et al. Erect leaves caused by brassinosteroid deficiency increase biomass production and grain yield in rice. Nature Biotechnol. 2006, 24, 105-109.

[87] Choe, S., Dilkes, B.P., Fujioka, S., Takatsuto, S. et al. The DWF4 gene of Arabidopsis encodes a CytochromeP450 that mediates multiple $22 a$-hydroxylation steps in Brassinosteroid biosynthesis. Plant Cell 1998, 10, 231-243.

[88] Sakamoto, T., Morinaka, Y., Ishiyama, K., Kobayashi, M. et al. Genetic manipulation of gibberellin metabolism in rice. Nature Biotechnol. 2003, 21, 909-913.

[89] Busov, V. B., Brunner, A. M., Strauss, S. H. Genes for control of plant stature and form. New Phytol. 2008, 177, 589-607. 
[90] McCallum, C. M., Comai, L., Greene, E. A., Henikoff, S. Targeting induced local lesions IN genomes (TILLING) for plant functional genomics. Plant Physiol. 2000, 123, 439442.

[91] Slade, A. J., Fuerstenberg, S. I., Loeffler, D., Steine, M. N. et al. A reverse genetic, nontransgenic approach to wheat crop improvement by TILLING. Nature Biotechnol. $2005,23,75-81$. 
Table 1.

\begin{tabular}{|c|c|c|c|c|c|}
\hline Gene/Locus & $\begin{array}{l}\text { Hormone } \\
\text { involved }\end{array}$ & Species & Mutant/transgenic & Phenotype & Reference \\
\hline $\begin{array}{c}s d 1 \\
(G A 20 o x \\
\text { gene) }\end{array}$ & GA & rice & mutant & $\begin{array}{l}\text { Semi-dwarfed } \\
\text { plants }\end{array}$ & [12] \\
\hline $\begin{array}{c}R h t(D E L L A \\
\text { gene) }\end{array}$ & GA & wheat & mutant & $\begin{array}{l}\text { Decreased } \\
\text { plant height, } \\
\text { response to } \\
\text { GA and } \\
\text { increased GA } \\
\text { levels }\end{array}$ & [25] \\
\hline $\begin{array}{c}\text { DhfH9- } \\
\text { iaaM }\end{array}$ & auxin & $\begin{array}{l}\text { strawberry, } \\
\text { raspberry }\end{array}$ & transgenic (sense) & $\begin{array}{l}\text { Increased } \\
\text { number of } \\
\text { fruits per } \\
\text { plant, } \\
\text { increased fruit } \\
\text { weight and } \\
\text { size }\end{array}$ & [34] \\
\hline SIIAA9 & auxin & tomato & $\begin{array}{l}\text { transgenic } \\
\text { (antisense) }\end{array}$ & $\begin{array}{l}\text { Parthenocarpic } \\
\text { fruits }\end{array}$ & [40] \\
\hline LeACS2 & ET & tomato & $\begin{array}{l}\text { transgenic } \\
\text { (antisense) }\end{array}$ & $\begin{array}{l}\text { Reduced } \\
\text { ripening- } \\
\text { related } \\
\text { synthesis of } \\
\text { ethylene to } \\
0.1 \% \text { of } \\
\text { control fruit, } \\
\text { abnormal } \\
\text { pattern of } \\
\text { ripening }\end{array}$ & [57] \\
\hline LeETR4 & ET & tomato & $\begin{array}{l}\text { transgenic } \\
\text { (antisense) }\end{array}$ & $\begin{array}{c}\text { ET } \\
\text { hypersensitive } \\
\text { phenotype } \\
\text { including } \\
\text { accelerated } \\
\text { ripening }\end{array}$ & [64] \\
\hline etrl.1 & ET & carnation & transgenic (sense) & $\begin{array}{l}\text { Cut flowers } \\
\text { had three } \\
\text { times the vase } \\
\text { life of non- } \\
\text { transformed }\end{array}$ & {$[68]$} \\
\hline Sho & $\mathrm{CK}$ & potato & transgenic (sense) & $\begin{array}{c}\text { Increased } \\
\text { shoot } \\
\text { production, } \\
\text { delayed tuber } \\
\text { formation, } \\
\text { decreased } \\
\text { tuber size and }\end{array}$ & [77] \\
\hline
\end{tabular}




\begin{tabular}{|l|l|l|l|c|c|}
\hline & & & $\begin{array}{c}\text { inhibition of } \\
\text { tuber } \\
\text { dormancy }\end{array}$ & \\
\hline osdwarf4-1 & BR & rice & mutant & $\begin{array}{c}\text { Increased } \\
\text { biomass and } \\
\text { grain } \\
\text { production }\end{array}$ & [86] \\
\hline
\end{tabular}


Victoriano Valpuesta is Professor at the Department of Biochemistry and Molecular Biology of the University of Málaga. He received a PhD in Biochemistry from the University of Sevilla and he gained a postdoc position in Michigan State University, working with Professor Martin J. Bukovac. In 1982 he was granted with a position as Professor in the University of Málaga, where he achieved the tenure as full Professor in 1990. Main research interest during this period was enzymology of the amino acids metabolism in plants. Afterwards he has spent two sabbaticals in the University of California in the laboratory of Dr. Michael S. Reid, and the University of Queensland in the laboratory of Dr. José R. Botella. His current research goals are centered on molecular studies of developmental processes in plants, mostly in fruits. His most recent research addresses the use of functional genomics tools in the ongoing research on plant development. 


1
1
3
4
5
6
7
8
9
10
11
12
13
14
15
16
17
18
19
20
21
22
23
24
25
26
27
28
29
30
31
32
33
34
35
36
37
38
39
40
41
42
43
44
55
50
56
57
48
59
50
51
53
50

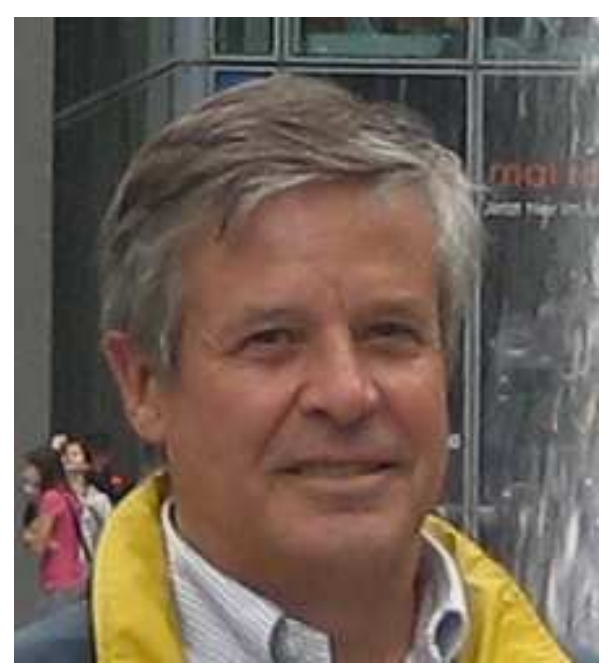

$31 \times 34 \mathrm{~mm}(180 \times 180$ DPI $)$

Wiley-VCH 